\title{
Airworthiness Support Measures Analogy to the Prospective Roundabouts Alternatives: Theoretical Aspects
}

\author{
Andriy Viktorovich Goncharenko (D) \\ Aircraft Airworthiness Retaining Department, Academic and Research Aerospace Institute, National Aviation University, \\ 1, Kosmonavta Komarova Avenue, Kyiv 03058, Ukraine
}

Correspondence should be addressed to Andriy Viktorovich Goncharenko; andygoncharenco@yahoo.com

Received 11 May 2018; Accepted 4 October 2018; Published 6 November 2018

Guest Editor: Raffaele Mauro

Copyright (C) 2018 Andriy Viktorovich Goncharenko. This is an open access article distributed under the Creative Commons Attribution License, which permits unrestricted use, distribution, and reproduction in any medium, provided the original work is properly cited.

\begin{abstract}
The goal of this paper is to investigate theoretically the possible directions of some specified methods for the alternative roundabouts effectiveness modeling and optimization. The out-coming criteria have an economical interpretation. Those are the objective functionals of the alternative roundabouts effectiveness as the profit gained in the course of the traffic flow changes in the view of the integral form. This is modeled taking into consideration the transport infrastructure functioning elements such as the traffic flow of a capacity model. It takes into account two major components of the transportation services which are the alternative roundabouts business' incomes and expenses relating to the roundabouts transportation worthiness support. The prototypic approach is that one from the aircraft airworthiness support measures models. Corresponding managerial influences with respect to environmental, safety, utility, and other issues, as well as probable impacts, are modeled with the construction of the relevant under-integral expressions, equations, and appropriate coefficients and parameters of the mathematical models. The achieved theoretical results, on the basis of the Euler-Lagrange equation and accepted assumptions, have been checked for the sufficiency of the objective functional maximum presence at the "point" with the use of the conducted computer simulation. The necessary diagrams are plotted in order to illustrate the theoretical contemplations and speculations, as well as to check the correctness of the applied mathematical derivations and visualize the models' preciseness and abilities. The theoretically constructed mathematical models have a significance of the prognostic values applicability required at the alternative roundabouts effectiveness modeling and optimization ensuring their design progress and evolutions.
\end{abstract}

\section{Introduction}

The complexity of the modern roundabouts design, their diversities in designations, and functional, economic, and environmental criteria structures elaboration [1] are predetermining the multialternativeness of the new types of the roundabouts evaluation.

Rational economic activity is the foundation providing the development in all areas and spheres of life [2]. Therefore, theoretical researches with the help of the plausibly developed hypothetical mathematical models are of a great importance [2]; moreover, the usefulness of such models application for the alternative roundabouts effectiveness evaluations is beyond any doubts and it can be traced with the most upto-date publications [3-15]. The brief literature survey of the presented paper just is highlighting the principal possibilities of the proposed methods implementations in those areas of science that relate with the multiattribute assessment of road design solutions [3], geometric design of turbo roundabouts [4], or the journal paper [5] dedicated to the turbo roundabouts, design principles, and safety performance, as well as alternativeness [6] and transportation infrastructure [7] aspects.

It is also necessary to underline the importance of the developed here approach for other transportation facilities, like railway [8]; however the methods are aimed at modeling alternative roundabouts effectiveness and in its sense continue the researches of the assessment, analysis, and simulation discussed in references [9-15]. Some of those publications emphasize the evaluation of the environmental and functional benefits of "innovative" roundabouts situational 
features, like [11] or the study of the vehicle speed [14] for the design of the roundabouts.

Remarkable in this context is that all the publications either directly or indirectly have dealt or might have dealt with mathematical modeling and simulation in regard to economical parameters.

One of such approaches and corresponding mathematical modeling is the objective of the presented paper.

There are numerous strategies to cope with the problems related with transportation services in general. The diversity of such strategies is stipulated by different types of transportation means, other managerial factors, including financial levers of influence.

For example, in Belgium, as that was reported by the TV news and broadcasted by the mass media, the local subway service becomes free of charge; no one will have to pay in fares, when the on-ground going vehicles' pollutant emission exceeds the accepted allowed limits.

The presented paper theoretical concept is centered upon the issues related with the support of the alternative roundabouts worthiness (vehicle worthiness, riding worthiness, transportation worthiness, etc.). The prototypic approach is adopted from the aircraft airworthiness support measures concepts of [16-20] developed from subjective analysis [21] on the basis of the Jaynes' principle [22-24] in the framework of the calculus of variations theory [25].

\section{Mathematical Modeling and Developed Methods}

There is an irresistible temptation to model and investigate the process of a roundabout functioning under the prism of its effectiveness. It will depend upon the number of factors; specialists, who have an extensive experience in the field of roundabouts, distinguish the most significant from them [1,3-15]. It is proposed to consider theoretically the modeling and optimizing of a few, for example, competing roundabouts. The supposed roundabouts worthiness is deemed to be supported in an analogous to airworthiness way [16-20].

2.1. Basic Model. Every aspect of a roundabout functioning is being considered under the prism of multialternativeness, if it deals with someone's choice or individual subjective preferences distribution in regard to the achievable set of alternatives [21], on one hand. And on the other hand, there is a multi- "optionality" phenomenon when the objectively existing options of the ongoing processes are under consideration.

All the issues of a roundabout operation or exploitation relating transportation facilities, network, entire and in particular infrastructure capacity, functional and economical criteria, environmental impacts, safety and precaution means and measures are based upon operational incomes and costs analysis [2].

Profitableness of a roundabout construction along with the roundabout's design, creation, building, and management costs subtracted from the incomes ensures a good reaction of the transportation business upon the challenges of the functioning [1-15].
Herewith, it is proposed a model based upon the principle approach expressed with the following formula:

$$
J=\int_{p_{0}}^{p_{1}}\left(a p c c^{\prime}-b p c^{\prime}\right) d p .
$$

Here, in equation (1), $J$ is the objectives functional depending upon the variated traffic flow $p$ within the traffic flow's possible range of alterations $\left[p_{0} \ldots p_{1}\right]$. The underintegral function of

$$
a p c c^{\prime}-b p c^{\prime}
$$

expresses the specific profitableness of the roundabout, reduced per a vehicle in the roundabout's varied traffic flow. In the expressions of (1) and (2), $a$ has a meaning of the proportionality coefficient for the supposed model of the incomes formation, whereas $b$ bears a sense of such a coefficient for the accepted costs model. The function of $c$ takes its own role in the roundabout's operational income versus cost balance formation. For the stated problem setting, it is investigated the model constructed of the expressions of (1) and (2), being also dependent upon the first complete derivative of

$$
c^{\prime}=\frac{d c}{d p}=c_{p}^{\prime} .
$$

Mathematically, formulated in the view of the equations of (1) - (2), this particularly given problem setting is stated as the simplest problem of the calculus of variations for the objective functionals likewise [25]:

$$
J=\int_{p_{0}}^{p_{1}} F\left(p, c, c_{p}^{\prime}\right) d p
$$

where $F\left(p, c, c_{p}^{\prime}\right)$ is the under-integral function of the stated problem objective functional (1).

That is,

$$
F\left(p, c, c_{p}^{\prime}\right)=a p c c_{p}^{\prime}-b p c_{p}^{\prime} .
$$

The purpose is to maximize the objective functional (1) on conditions of (2) and (3) by finding such function of $c$ that delivers the wanted maximum of the profit formation; and for the general view integral of (4) there are the necessary conditions for the extremum existence in the view of the wellknown Euler-Lagrange equation [25]:

$$
\frac{\partial F}{\partial c}-\frac{d}{d p}\left(\frac{\partial F}{\partial c_{p}^{\prime}}\right)=0 .
$$

2.2. Solution to the Stated Basic Profit Optimization Problem. In previous speculations (1) - (6) framework mentioned above, the sought after solution will be next.

In accordance with the Euler-Lagrange equation (6) [25], in case of (1) - (5)

$$
\frac{\partial F}{\partial c}=a p c_{p}^{\prime}
$$


Then, for the second member of equation (6) that condition yields

$$
\frac{\partial F}{\partial c_{p}^{\prime}}=a p c-b p
$$

Differentiating the partial derivative of the right hand part of equation (8) for the second time with respect to the independent variable $p$ in the complete form derivative it can be obtained that

$$
\begin{aligned}
\frac{d}{d p}\left(\frac{\partial F}{\partial c_{p}^{\prime}}\right)= & \frac{\partial}{\partial p}\left(\frac{\partial F}{\partial c_{p}^{\prime}}\right) \frac{d p}{d p}+\frac{\partial}{\partial c}\left(\frac{\partial F}{\partial c_{p}^{\prime}}\right) \frac{d c}{d p} \\
& +\frac{\partial}{\partial c_{p}^{\prime}}\left(\frac{\partial F}{\partial c_{p}^{\prime}}\right) c_{p}^{\prime \prime},
\end{aligned}
$$

where

$$
\partial c_{p}^{\prime \prime}=\frac{d^{2} c}{d p^{2}} .
$$

Thus, with taking into account the conditions written with the equations of (9) and (10), for equations (6) and (8) it yields

$$
\frac{d}{d p}\left(\frac{\partial F}{\partial c_{p}^{\prime}}\right)=a c-b+a p c_{p}^{\prime}
$$

Here in (11) the complete derivative (9) has got an abridged form since

$$
\frac{\partial}{\partial c_{p}^{\prime}}\left(\frac{\partial F}{\partial c_{p}^{\prime}}\right) \equiv 0
$$

Hence, the second derivative (10) is omitted in the final form of the Euler-Lagrange equation (6); and equation (6) now does not depend upon the second derivative of the sought function, i.e.,

$$
\frac{\partial}{\partial c_{p}^{\prime}}\left(\frac{\partial F}{\partial c_{p}^{\prime}}\right) c_{p}^{\prime \prime} \equiv 0
$$

Therefore, substituting the relevant expressions of (7) and (11) for their values into the equation (6), it becomes possible to rewrite it in the view of

$$
a p c_{p}^{\prime}-\left(a c-b+a p c_{p}^{\prime}\right)=0 .
$$

Finally, after cancelling the similar members in equation (14), it yields even not a differential but algebraic equation with respect to the function of $c$, that determines the considered model structure (1):

$$
a c-b=0 .
$$

Furthermore, the solution in the view of function $c$ has happened to be not depending upon the independent variable $p$ at all:

$$
c=\frac{b}{a}
$$

2.3. Another Model a Roundabout Functioning. It is definitely the simplest model described with expressions of (1) - (5) and yielding the solution in the view of equation (16) obtained through the procedures of (6) - (16) should be checked for the suspected extremum existence since all mathematical constructions and derivations have been performed on the basis of the necessity conditions (6).

Another theoretical development of the model of (1) - (5) applicable for an alternative roundabout functioning is as the following one.

Suppose, there is a nonlinear (raised to a certain power) dependence of the profitableness function (under-integral function) of $F$ upon the traffic flow $p$. Herein, it is proposed the next up modification (see and compare with the equation of (5)):

$$
F\left(p, c, c_{p}^{\prime}\right)=a p^{n} c c_{p}^{\prime}-b p c_{p}^{\prime},
$$

where $n$ is the power index magnifying the impact of the traffic flow $p$ exerted upon the component of the vehicle contribution in the traffic flow.

The theoretical solution to the objective functional similar to (1) or (4), in the framework of the approach analogous to (6) - (16), results in the other view optimal function.

However, it is obvious, in the proposed model modification expressed with the equation of (17) versus (5), the principle of the wanted solution finding will not differ from the traditional method (6).

2.4. Developed Model Solution. The substitution of the relevant interrelationship of (17) pertaining with the stated problem setting for its value into the objective functional (1) gives for members of equation (6) such formulae.

For the partial derivative with respect to the sought function, likewise (7), the expression will be in accordance with the model equation (17):

$$
\frac{\partial F}{\partial c}=a p^{n} c_{p}^{\prime}
$$

For the complete derivative, similar to (9), with respect to the independent variable, the partial derivative with respect to the complete derivative of the sought function with respect to the independent variable, in analogous way to (8), now gets the view of the following equation:

$$
\frac{\partial F}{\partial c_{p}^{\prime}}=a p^{n} c-b p
$$

In its turn the complete form derivative (9) in such case yields similar to (11)

$$
\frac{d}{d p}\left(\frac{\partial F}{\partial c_{p}^{\prime}}\right)=a n p^{n-1} c-b+a p^{n} c_{p}^{\prime} .
$$

After that collecting corresponding members of equations (18) and (20) into the necessary condition EulerLagrange equation (6), there is a possibility to obtain the other equation than (14), i.e.,

$$
a p^{n} c_{p}^{\prime}-\left(a n p^{n-1} c-b+a p^{n} c_{p}^{\prime}\right)=0 .
$$


Again, making obvious transformations, (21) yields the needed result as the following equation:

$$
a n p^{n-1} c-b=0 .
$$

From (22) it inevitably means formula (23):

$$
c=\frac{b}{a n p^{n-1}}=c(p) .
$$

This time, unlike in the case resulting with the constant value of (16), the sought solution (23) of the model (17) - (23) is a certain function of the independent variable, traffic flow $p: c(p)$.

\subsection{Computer Simulation and Check of the Suspected Solutions} Optimality. As the solutions in the view of equations (16) and (23) are found on just the necessary condition (6) for the extremums existence, it is required to check the solutions for being really optimal subject to the stated problem settings constraints.

The numerical data for the conducted calculation experimentation are as follows. For the basic model described with the procedures of expressions (1) - (16): $a=2 ; b=20$ of such Conditional Units (CU) that are correspond to the measurement units of the fractional members of the underintegral function (5) of the objective functional (1). The range of the traffic flow $p$ alteration has been considered from $p_{0}=$ 1 up to $p_{1}=200$ of CU (possible unit is vehicles per an hour $(\mathrm{v} / \mathrm{h}))$. The result of such primitive, so far, experimentation is $c=10 \mathrm{CU}$.

In order to make sure of the optimality of the obtained function $c=10$ value, it is possible to let the function $c=10$ some definite variation with the fixed boundaries.

Such effect is modelled with the help of the matrix-vector data description.

The traffic flow matrix at the next three specified points is

$$
\mathbf{P}=\left[\begin{array}{ccc}
p_{0}^{2} & p_{0} & 1 \\
\left(\frac{p_{0}+p_{1}}{2}\right)^{2} & \frac{p_{0}+p_{1}}{2} & 1 \\
p_{1}^{2} & p_{1} & 1
\end{array}\right]
$$

The column-vector of the free function values difference is given in the view of

$$
\mathbf{C}=\left[\begin{array}{c}
0 \\
-0.0005 \cdot c_{\mathrm{opt}}\left(\frac{p_{0}+p_{1}}{2}\right) \\
0
\end{array}\right],
$$

where $c_{\text {opt }}\left(\left(p_{0}+p_{1}\right) / 2\right)$ depicts the modeled variated function interrelationships between the alternating traffic flow $p$ in $\mathrm{v} / \mathrm{h}$ and the function's optimal value of equation (16) $c_{\mathrm{opt}}=10$ $\mathrm{CU}$ in the middle of the accepted range of the traffic flow $p$ variation.

Now, from the matrix-vector equation engaging the equations of (24) and (25)

$$
\mathbf{C}=\mathbf{P} \cdot \mathbf{K},
$$

where

$$
\mathbf{K}=\left[\begin{array}{l}
a_{1} \\
b_{1} \\
c_{1}
\end{array}\right]
$$

where $a_{1}, b_{1}$, and $c_{1}$ are the coefficients, in CU, converting the traffic flow values of the quadratic forms of (24) via (26) with (27) into the free function values of (25).

Solving for (27) it returns

$$
\mathbf{K}=\mathbf{P}^{-1} \cdot \mathbf{C} \text {. }
$$

And for the inverse matrix it yields

$$
\mathbf{P}^{-1}=\left[\begin{array}{ccc}
\frac{2}{39,601} & -\frac{4}{39,601} & \frac{2}{39,601} \\
-\frac{601}{39,601} & \frac{804}{39,601} & -\frac{203}{39,601} \\
\frac{40,200}{39,601} & -\frac{800}{39,601} & \frac{201}{39,601}
\end{array}\right] .
$$

This gives

$$
\mathbf{K}=\left[\begin{array}{c}
a_{1}=5.05 \cdot 10^{-7} \\
b_{1}=-1.015 \cdot 10^{-4} \\
c_{1}=1.01 \cdot 10^{-4}
\end{array}\right] .
$$

In accordance with the expressions of the procedure of (24) - (30) the free function variations calculated by

$$
c_{o}(p)=a_{1} p^{2}+b_{1} p+c_{1}+c_{\mathrm{opt}}(p)
$$

for a decreasing function variation and

$$
c_{O}(p)=-\left(a_{1} p^{2}+b_{1} p+c_{1}\right)+c_{\mathrm{opt}}(p)
$$

for an increasing function variation, illustrated in Figure 1, give the results shown in Figures 2 and 3.

In Figure $1 \mathrm{c}_{\mathrm{opt}}(\mathrm{p})$ is standing for the formula (16) extremal value of the optimal function; $c_{o}(p)$ has been calculated by formula (31) and $\mathrm{c}_{\mathrm{O}}(\mathrm{p})$ by formula (32).

In Figure $2 \mathrm{Z}_{\text {opt }}(\mathrm{p}), \mathrm{Z}_{\mathrm{o}}(\mathrm{p})$, and $\mathrm{Z}_{\mathrm{O}}(\mathrm{p})$ are the objective functionals values plotted as a result of the calculations performed by the formula (1) with the variated upper limit of integration for the corresponding determining functions of $c_{\text {opt }}(p)$ by the formula (16): extremal value of the optimal function; $\mathrm{c}_{\mathrm{o}}(\mathrm{p})$ by formula $(31) ; \mathrm{c}_{\mathrm{O}}(\mathrm{p})$ by formula (32).

And in Figure 3 the corresponding objective functionals values are plotted for the marginal traffic flow value $p_{1}=200$ $\mathrm{v} / \mathrm{h}$.

The nonlinear no constant model (17) - (23) numerical investigation is illustrated in Figures 4-6.

The optimal solution now is being calculated by the extremal formula of (23) and it has been variated in the style of the one described with the expression of (24) - (32). 


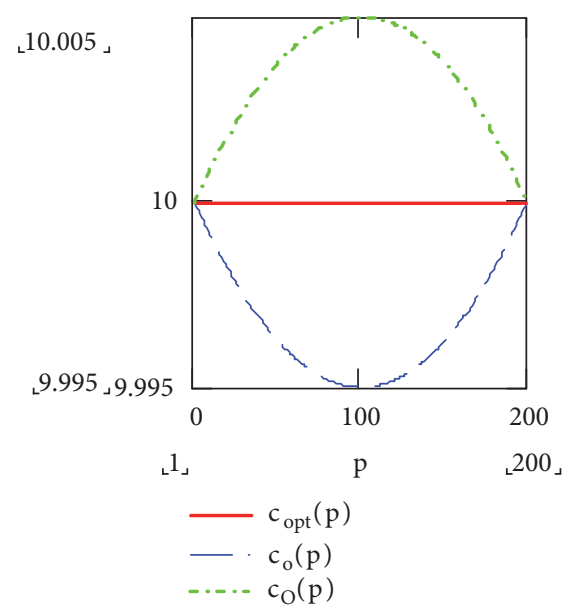

FIGURE 1: Free function variations for the traffic flow in comparison with the extremal solution (optimal function).

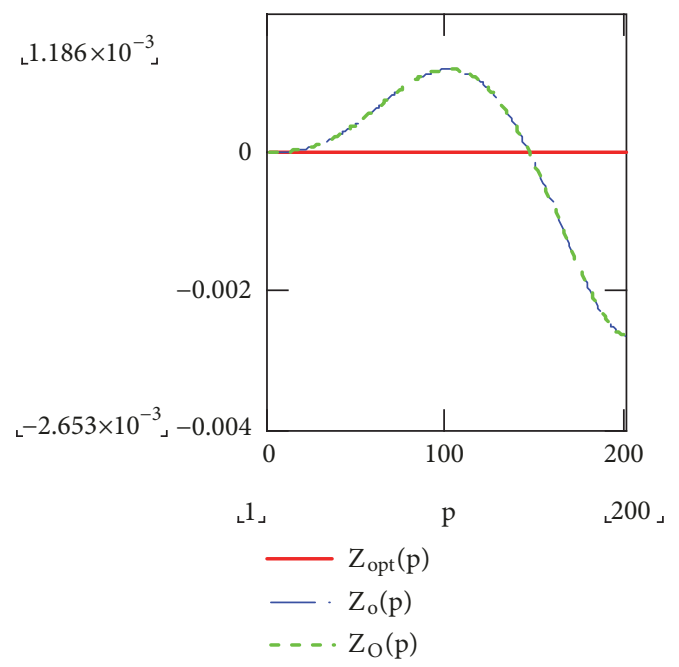

FIGURE 2: Objective functional value.

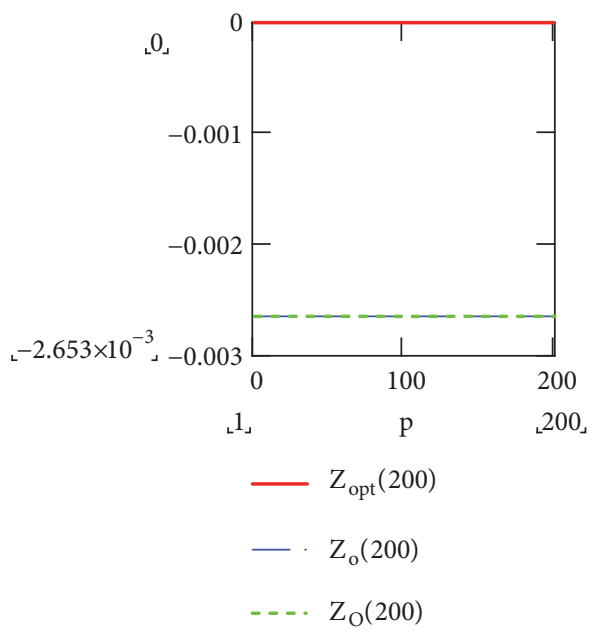

FIgURE 3: Objective functional value at the final boundary.

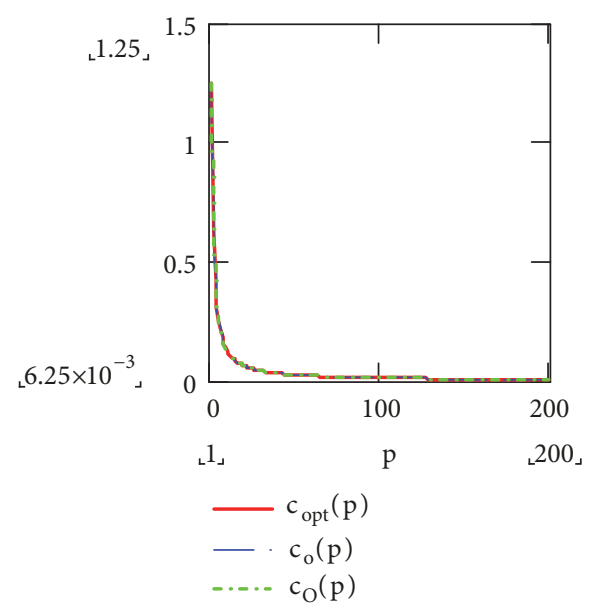

FIGURE 4: Free function variations for the traffic flow in comparison with the extremal solution (optimal function).

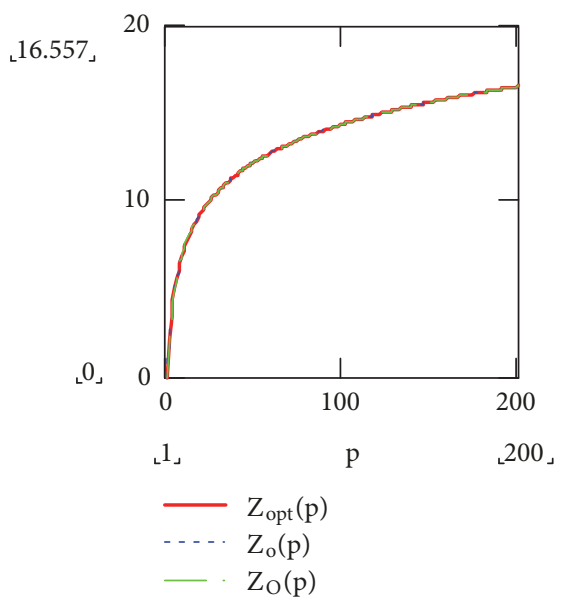

Figure 5: Objective functional value.

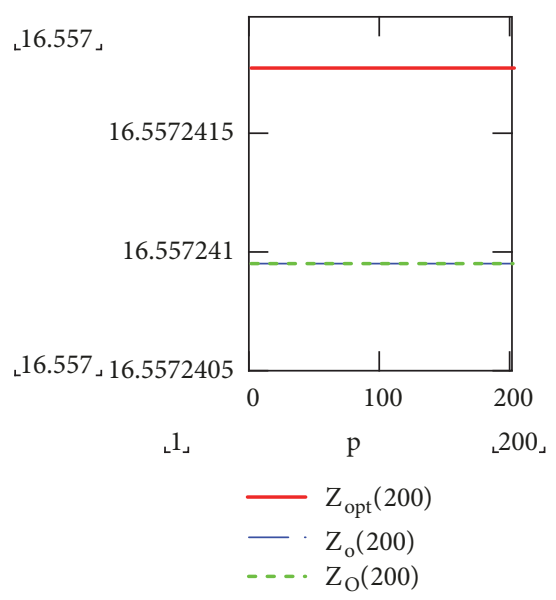

Figure 6: Objective functional value at the final boundary. 


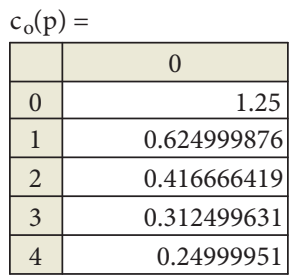

$\mathrm{c}_{\mathrm{o}}(\mathrm{p})=$
\begin{tabular}{|l|r|}
\hline & \multicolumn{1}{c|}{0} \\
\hline 195 & $6.377061058 \cdot 10^{-3}$ \\
\hline 196 & $6.344808309 \cdot 10^{-3}$ \\
\hline 197 & $6.31288382 \cdot 10^{-3}$ \\
\hline 198 & $6.28128266 \cdot 10^{-3}$ \\
\hline 199 & $6.25 \cdot 10^{-3}$ \\
\hline
\end{tabular}

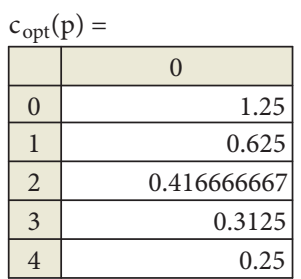

$\mathrm{c}_{\text {opt }}(\mathrm{p})=$
\begin{tabular}{|l|r|}
\hline & 0 \\
\hline 195 & $6.37755102 \cdot 10^{-3}$ \\
\hline 196 & $6.345177665 \cdot 10^{-3}$ \\
\hline 197 & $6.313131313 \cdot 10^{-3}$ \\
\hline 198 & $6.281407035 \cdot 10^{-3}$ \\
\hline 199 & $6.25 \cdot 10^{-3}$ \\
\hline
\end{tabular}

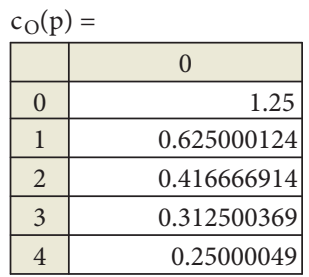

$\mathrm{c}_{\mathrm{O}}(\mathrm{p})=$
\begin{tabular}{|l|r|}
\hline & \multicolumn{1}{c|}{0} \\
\hline 195 & $6.378040982 \cdot 10^{-3}$ \\
\hline 196 & $6.345547021 \cdot 10^{-3}$ \\
\hline 197 & $6.313378807 \cdot 10^{-3}$ \\
\hline 198 & $6.28153141 \cdot 10^{-3}$ \\
\hline 199 & $6.25 \cdot 10^{-3}$ \\
\hline
\end{tabular}

FIGURE 7: Initial and final values of the variated determining free function.

The difference is for the accepted in the computerized numerical experimentations vector solution (30), which makes

$$
\mathbf{K}=\left[\begin{array}{c}
a_{1}=6.282 \cdot 10^{-10} \\
b_{1}=-1.263 \cdot 10^{-7} \\
c_{1}=1.256 \cdot 10^{-7}
\end{array}\right] \text {. }
$$

\section{Results and Discussion}

3.1. Analysis of the Obtained Results. The obtained theoretical results represented with the diagrams shown in Figures 1-6 brightly distinguish the described above two variants of the roundabouts functional strategies.

The maximal value of the objective functional is clearly seen in Figures 2 and 3 for the basic case (1) - (16) simulated with the procedures (24) - (32).

For a more complicated case study (17) - (23) calculated with (24) - (29) and (31) - (33) the effect of the maximization is hardly noticeable (see Figure 5) because of the tiny variations of the determining function values of $c_{\mathrm{opt}}(p)$ : found with the use of the extremal solution equation (23) (see Figure 4).

Nevertheless, even such negligibly small variations as proposed herewith prove the maximum value deliverance to the objective functional (1) with the under-integral function (17) and corresponding extremal (23) (see Figure 6).

3.2. Discussion. Theoretically, the obtained results are for a rather simple modeling. Nonetheless, the principle is fundamental: the profit is the difference between the incomes and costs of any object (including roundabouts) functioning. And the amount of the profit provides all necessary factors, which are numerous, with their implementation procedures and further outcomes.

The other fact of the simplifications accepted at the modeling is that the problem setting is stated for the fixed boundaries calculus of variations problem.
It is perfectly visible in Figure 1. This approach is applied in the (17) - (23) model too. To make a proof for such statement a couple of the fragmental parts pieces of the calculation tables are presented in Figure 7.

Moreover, all the theoretically considered factors [115] have a subjective analysis [21], based upon [22-24], component worth of being studied as a developmental idea of [16-20].

\section{Conclusions}

The theoretical concepts case study, analyzed in this paper on the alternative roundabouts worthiness in the way analogous to the aircraft airworthiness supporting measures effectiveness research, proves that the described calculus of variations approach allows obtaining the objectively existing optimal values of the operational (functioning) purpose functional with the help of the specially introduced determining functions.

Conditions of multialternativeness for the considered theoretically different types of the roundabouts are embodied with the corresponding parameters of the proposed models. The conditions of uncertainty related with the roundabouts alternatives can be taken into account with the subjective entropy of the individuals preferences functions optimal distributions.

The preferences functions give the possibility of the considered alternative roundabouts assessment with respect to the preferences entropy uncertainty measure, which should be a part of the further research dedicated to the theory of subjective analysis since it would be useful to find more theoretical results and applicable areas as well as some other effectiveness functions and their variables.

\section{Data Availability}

The data used to support the findings of this study are included within the article. 


\section{Conflicts of Interest}

The author declares that there is no conflict of interests regarding the publication of this paper.

\section{References}

[1] T. Tollazzi, G. Tesoriere, M. Guerrieri, and T. Campisi, "Environmental, functional and economic criteria for comparing "target roundabouts" with one- or two-level roundabout intersections," Transportation Research Part D: Transport and Environment, vol. 34, pp. 330-344, 2015.

[2] E. Silberberg and W. Suen, The Structure of Economics. A Mathematical Analysis, McGraw-Hill Higher Education, 2001.

[3] E. K. Zavadskas, "Multi-attribute assessment of road design solutions by using the COPRAS method," The Baltic Journal of Road and Bridge Engineering, vol. 2, no. 4, pp. 195-203, 2007.

[4] T. Džambas, S. Ahac, and V. Dragčević, "Geometric design of turbo roundabouts," Tehnički vjesnik, vol. 24, no. 1, pp. 309-318, 2017.

[5] L. G. H. Fortuijn, “Turbo roundabouts: Design principles and safety performance," Journal of the Transportation Research Board, vol. 2096, no. 1, pp. 16-24, 2009.

[6] J. C. Engelsman and M. Uken, "Turbo roundabouts as an alternative to two lane roundabouts," in Proceedings of the 26th Annual Southern African Transport Conference, SATC '07, pp. 581-589, Pretoria, South Africa, 2007.

[7] Z. Tesoriere, "Infrastructure as interface: Thinking the urban and the high-speed railway station: Italian case-studies," Spaces \& Flows: An International Journal of Urban \& Extra Urban Studies, vol. 3, no. 1, pp. 71-87, 2013.

[8] A. Cazzani, M. Cattani, R. Mauro, and F. Stochino, "A simplified model for railway catenary wire dynamics," European Journal of Environmental and Civil Engineering, vol. 21, no. 7-8, pp. 936959, 2017.

[9] O. Giuffrè, A. Granà, and S. Marino, "Comparing performances of turbo-roundabouts and double-lane roundabouts," Modern Applied Science, vol. 6, no. 10, pp. 70-79, 2012.

[10] A. B. Silva, P. Mariano, and J. P. Silva, "Performance Assessment of Turbo-roundabouts in Corridors," Transportation Research Procedia, vol. 10, pp. 124-133, 2015.

[11] M. Guerrieri, F. Corriere, B. Lo Casto, and G. Rizzo, "A model for evaluating the environmental and functional benefits of "innovative" roundabouts," Transportation Research Part D: Transport and Environment, vol. 39, pp. 1-16, 2015.

[12] L. Vasconcelos, A. Silva, Á. Seco, P. Fernandes, and M. Coelho, "Turboroundabouts: multicriterion assessment of intersection capacity, safety, and emissions," Transportation Research Record: Journal of the Transportation Research Board, vol. 2402, pp. 2837,2014

[13] D. Ticali and F. Corriere, "Turbo roundabouts: geometric design parameters and performance analysis," GSTF Journal on Computing (JoC), vol. 2, no. 1, pp. 227-232, 2012.

[14] H. Pilko, D. Brčić, and N. Šubić, "Study of vehicle speed in the design of roundabouts," Gradevinar-Journal of the Croatian Association of Civil Engineers, vol. 66, no. 5, pp. 407-416, 2014.

[15] J. Chalmovský, J. Štefaňák, L. Miča et al., "Statistical-numerical analysis for pullout tests of ground anchors," The Baltic Journal of Road and Bridge Engineering, vol. 12, no. 3, pp. 145-153, 2017.
[16] A. V. Goncharenko, "Aeronautical and aerospace material and structural damages to failures: theoretical concepts," International Journal of Aerospace Engineering, vol. 2018, Article ID 4126085, 7 pages, 2018.

[17] A. V. Goncharenko, "Multi-optional hybrid effectiveness functions optimality doctrine for maintenance purposes," in Proceedings of the 2018 IEEE 14th International Conference on Advanced Trends in Radioelecrtronics, Telecommunications and Computer Engineering (TCSET '18), pp. 771-775, IEEE, LvivSlavske, Ukraine, 2018.

[18] A. Goncharenko, "Aircraft operation depending upon the uncertainty of maintenance alternatives," Aviation, vol. 21, no. 4, pp. 126-131, 2017.

[19] A. V. Goncharenko, "Optimal UAV maintenance periodicity obtained on the multi-optional basis," in Proceedings of the 2017 IEEE 4th International Conference Actual Problems of Unmanned Aerial Vehicles Developments (APUAVD '17), pp. 6568, IEEE, Kiev, Ukraine, 2017.

[20] A. Goncharenko, "Several models of artificial intelligence elements for airctaft control," in Proceedings of the 2016 IEEE 4th International Conference on Methods and Systems of Navigation and Motion Control (MSNMC '16), pp. 224-227, IEEE, Kiev, Ukraine, 2016.

[21] V. Kasianov, Subjective Entropy of Preferences. Subjective Analysis: Monograph, Institute of Aviation, Warsaw, Poland, 2013, http://kasianovv.wixsite.com/entropyofpreferences.

[22] E. T. Jaynes, "Information theory and statistical mechanics," Physical Review A: Atomic, Molecular and Optical Physics, vol. 106, pp. 620-630, 1957.

[23] E. T. Jaynes, "Information theory and statistical mechanics II," Physical Review A: Atomic, Molecular and Optical Physics, vol. 108, pp. 171-190, 1957.

[24] E. T. Jaynes, "On The Rationale of Maximum-Entropy Methods," Proceedings of the IEEE, vol. 70, no. 9, pp. 939-952, 1982.

[25] I. M. Gelfand and S. V. Fomin, Calculus of Variations, State Publishing House of Physical and Mathematical Literature, Moscow, Russia, 1961. 


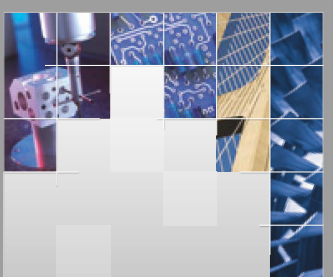

\section{Enfincering}
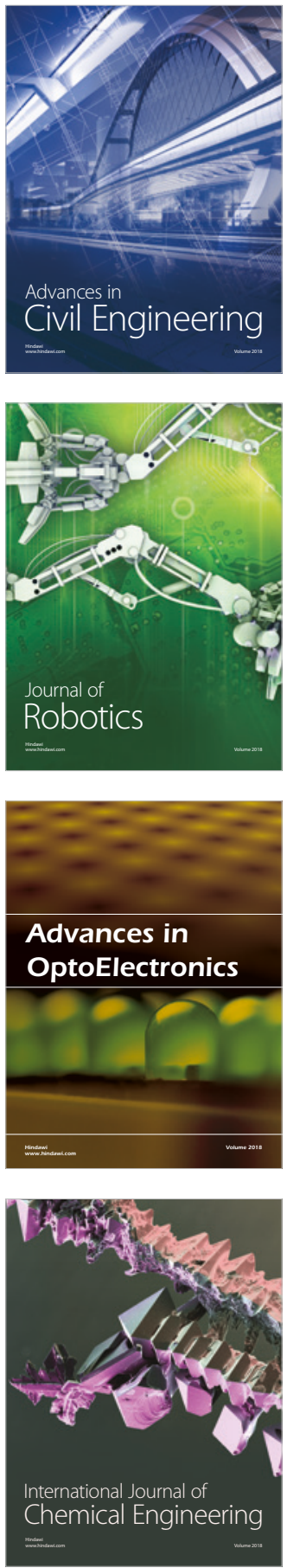

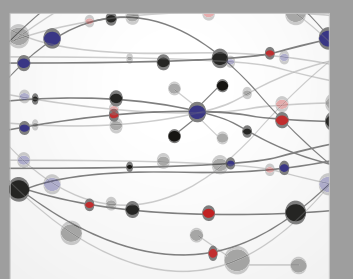

\section{Rotating \\ Machinery}

The Scientific World Journal

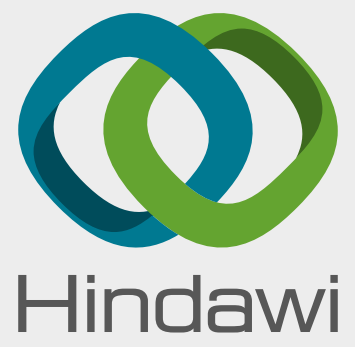

Submit your manuscripts at

www.hindawi.com
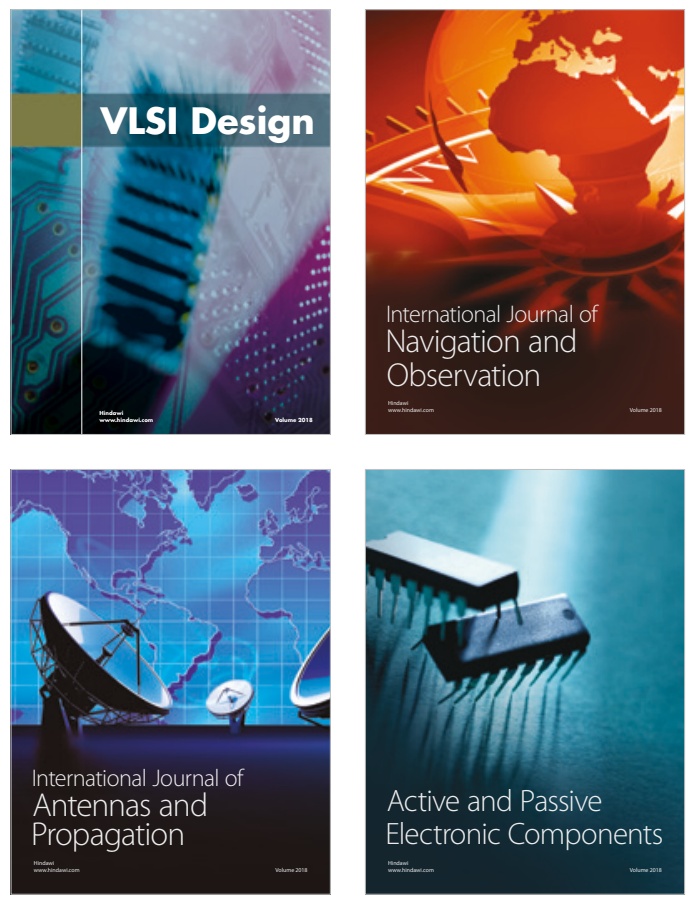
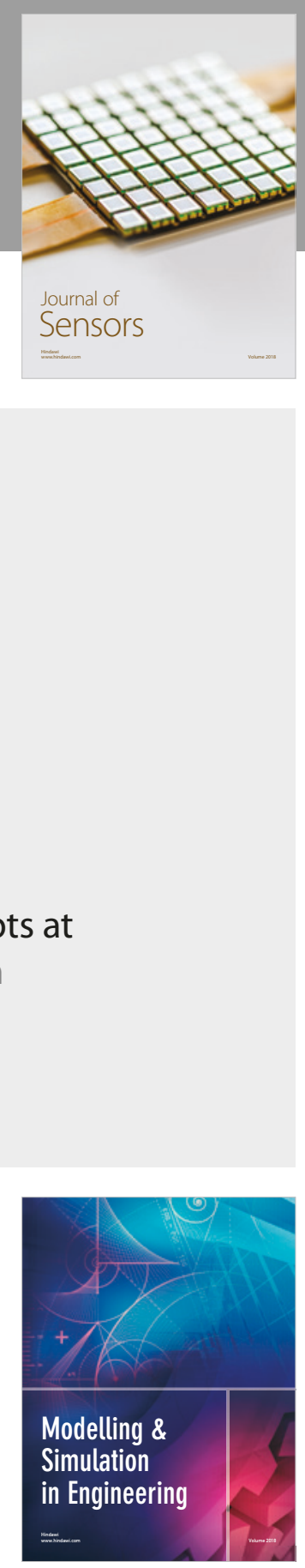

\section{Advances \\ Multimedia}
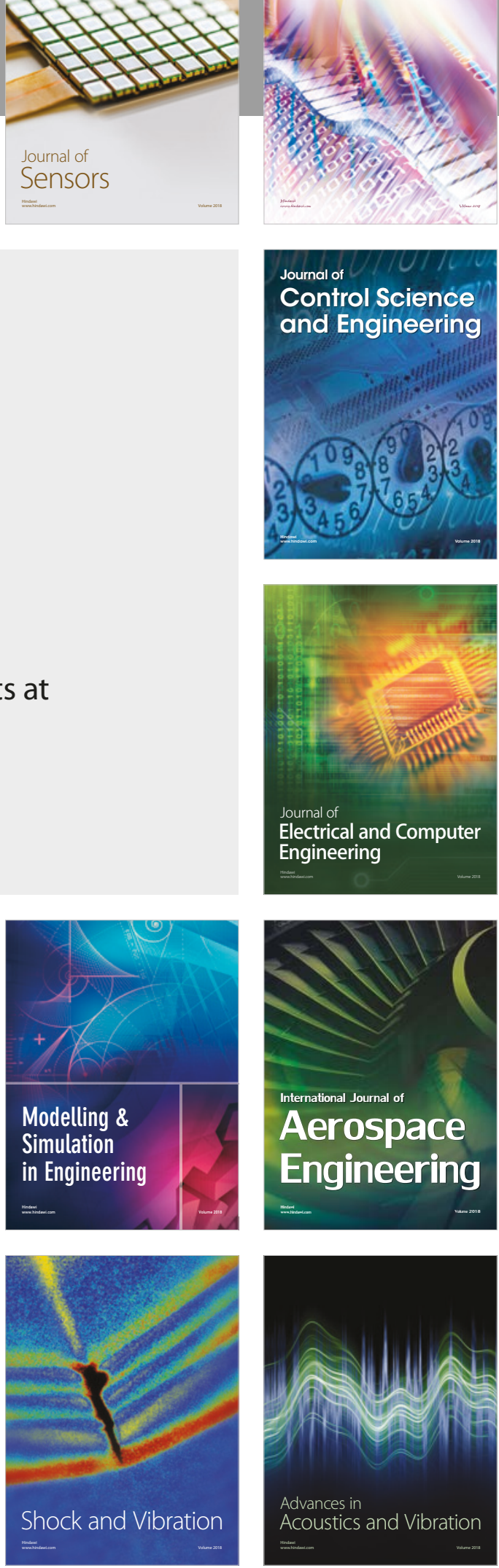